\title{
Do Diacritical Marks Play a Role at the Early Stages of Word Recognition in Arabic?
}

\author{
Manuel Perea ${ }^{1,2 *}$, Reem Abu Mallouh ${ }^{2}$, Ahmed Mohammed $^{2}$, Batoul Khalifa ${ }^{3}$ and \\ Manuel Carreiras ${ }^{2,4}$
}

${ }^{1}$ Department of Methodology, Universitat de València, Valencia, Spain, ${ }^{2}$ Basque Center on Cognition, Brain, and Language, Donostia, Spain, ${ }^{3}$ Psychological Sciences Department, Qatar University, Doha, Qatar, ${ }^{4}$ Ikerbasque Basque Foundation for Science, Billbao, Spain

OPEN ACCESS

Edited by:

Guillaume Thierry,

Bangor University, UK

Reviewed by:

Andrea Krott,

University of Birmingham, UK

Arthur M. Jacobs,

Free University of Berlin, Germany

*Correspondence: Manuel Perea mperea@uv.es

Specialty section: This article was submitted to

Language Sciences,

a section of the journal

Frontiers in Psychology

Received: 13 June 2016 Accepted: 08 August 2016 Published: 22 August 2016

Citation:

Perea M, Abu Mallouh $R$ Mohammed A, Khalifa $B$ and Carreiras M (2016) Do Diacritical Marks Play a Role at the Early Stages of Word Recognition in Arabic?

Front. Psychol. 7:1255. doi: 10.3389/fpsyg.2016.01255
A crucial question in the domain of visual word recognition is whether letter similarity plays a role in the early stages of visual word processing. Here we focused on Arabic because in this language there are various groups of letters that share the same basic shape and only differ in the number/location of diacritical points. We conducted a masked priming lexical decision experiment in which a target word was preceded by: (i) an identity prime; (ii) a prime in which the critical letter was replaced by a letter with the same shape that differed in the number of diacritics (e.g., صحفية - صخفبة); or (iii) a prime in which the critical letter was replaced by a letter with different shape (e.g., صحفية - صكفية). Results showed a sizable advantage of the identity condition over the two substituted-letter priming conditions (i.e., diacritical information is rapidly processed). Thus, diacritical marks play an essential role in the "feature letter" level of models of visual word recognition in Arabic.

Keywords: lexical access, masked priming, visual-letter similarity, lexical decision

\section{INTRODUCTION}

As reviewed by Grainger et al. (2016), models of visual word recognition in the Roman alphabet assume that the visual form of the word's component letters is quickly mapped onto abstract units irrespective of font, case, position, or size. These abstract letter units are the driving force behind the process of visual word recognition. This analysis is consistent with the available empirical evidence. For instance, in a masked priming experiment, Jacobs et al. (1995) found that the lowercase prime judge and the uppercase prime JUDGE were equally effective at activating the target word JUDGE (i.e., there was no advantage of the physically identical condition over the nominally identical condition). In an electrophysiological experiment, Vergara-Martínez et al. (2015) replicated this behavioral phenomenon and found a difference between judge-JUDGE and JUDGE- JUDGE in an early (visual) ERP component (N/P150) - this difference completely disappeared in orthographical-lexical components (N250 and N400). Similarly, Bowers et al. (1998) found an equivalent magnitude of masked identity priming, relative to an unrelated condition, for words that look visually similar across case (e.g., kiss-KISS) and for cross-case words that look visually dissimilar across case (e.g., gale-GALE). Finally, recent research has shown that visual similarity plays some role for briefly presented primes containing letter-like digits or symbols (e.g., M4TERI4L-MATERIAL faster than M6TERI6L-MATERIAL; see Perea et al., 2008), but these effects do not seem to occur for substituted-letter primes (e.g., the visually-similar prime HRHNDON does not facilitate the processing of the target abandon more than the control prime DWDNDON; see Kinoshita et al., 2013). 
In the present study, we examined whether visual-letter similarity plays a role at the early stages of word processing in another commonly-used script: Arabic. Unlike the Roman script, Arabic does not have a lowercase/uppercase distinction and it is read from right to left. In addition, some letters are connected to the following letter, but others are not-Arabic follows strict rules in this respect. Furthermore, the visual shape of the letters may look visually different depending on whether a letter is presented in isolation or in the initial, middle or final position within the letter chunk (e.g., the Arabic letter ayn looks quite different in an isolated position and in a middle position: $\varepsilon$ and, $\rightarrow$ respectively). To explore the role of visual similarity in Arabic, Perea et al. (2013) conducted a series of masked priming lexical decision experiments in which primes and targets had the same (visual) ligation pattern (e.g., كتاب ـ كتزب, ktzb-ktAb [book] with the Buckwalter transliteration) or not (كتاب ـ كتخب كتبر, ktxb-ktAb). Results showed remarkably similar word recognition times for these two substituted-letter conditions-there was only a similar advantage of these two conditions over an unrelated priming condition (e.g., كتاب_طبلر Tylr- ktAb). Perea et al. (2013) concluded that in Arabic, as occurs with the Roman script, there is access to "abstract letter representations in the early stages of visual word recognition" (p. 572). Similarly, in a masked prime same-different experiment with individuals who mastered both the Arabic and Roman scripts, Carreiras et al. (2013) found that the electrophysiological responses for Arabic letters (middle vs. isolated form) were similar to those for Roman letters (lowercase vs. uppercase); furthermore, the visual similarity effect disappeared in the P300 component in the two scripts. In addition, Yakup et al. (2015) failed to find a relationship between the magnitude of masked form priming and an estimated measure of visual similarity in Uyghur (i.e., a language which is written with Arabic script). Thus, despite the obvious differences between the visual processing of words in the Roman and Arabic scripts, the underlying processes seem be, to some degree, analogous (see Okano et al., 2013; for a similar observation regarding Japanese Katakana).

While the above-cited findings are undoubtedly important, one could argue that none of these experiments in Arabic directly manipulated visual-letter similarity. In the present research, we focused on a highly relevant feature of Arabic script related to visual-letter similarity. Most of the 28 Arabic letters share the basic shape with at least one other letter, so that they only differ in the number (or location) of diacritical points: (1) ص ص [the IPA codes are $/ \mathrm{d}^{\mathrm{S}} /$ and $/ \mathrm{s}^{\mathrm{Q}} /$, respectively]; (2) b and $b\left[/ \mathrm{z}^{\mathrm{f}} /\right.$ and $\left./ \mathrm{t}^{\mathrm{f}} /\right]$; (3) $\dot{\varepsilon}$ and $\varepsilon[/ \mathrm{\gamma} /$ and $/ \mathrm{S} /]$; (4) $\dot{\mathrm{s}}$ and $د$ [/ð/ and $\left./ \mathrm{d} /\right]$;

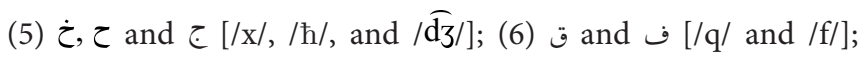
(7) $ش$ and $\omega / \int /$ and /s/]; (8) $j$ and $\rho[/ z /$ and /r/]; and (9) $\stackrel{ث}{\oplus}, \dot{ت}$, and $[/ \theta /, \mathrm{t} / \mathrm{t} /, / \mathrm{n} /$, and /b/]. Indeed, there was a time in the evolution of Arabic script in which the letters did not have diacritical points. That is, readers would need to deduce from context - and this was not always possible-whether a letter like, would correspond to /z/ or /r/. Around the 7th century, diacritical dots were added to the Arabic script to avoid this ambiguity, thus creating the letters for Classical Arabic. As a result, it is possible to create pairs of stimuli in Arabic that look visually very similar-i.e., the basic shape would be exactly the same. This allowed us to directly manipulate visual-letter similarity. As in prior research, we employed a masked priming lexical decision task. For each target word (e.g., صحفية SHfyp [journalist]), we created two substituted-letter primes: (a) a prime in which one of the letters from the target was replaced by another letter with the same basic shape (i.e., the only difference was the number of the diacritical points; صحفية - صخفية Sxfyp- SHfyp; same-shape substituted-letter prime); and (b) a prime in which the critical letter was replaced by another letter with a different basic shape (Skfyp- SHfyp; different-shape substituted-letter prime). As in previous research (e.g., Perea et al., 2013), we also included an identity priming condition for comparison purposes. Substituted-letter primes were always nonwords and involved the replacement of a root letter-note that Perea et al. (2014) reported a small but significant masked form priming effect in Arabic.

The predictions are the following: If we assume that early in word processing, there is some degree of uncertainty for those letter identities that share the basic shape, same-shape substituted-letter primes would enjoy some advantage over different-shape substituted-letter primes (e.g., صحفية - صخفية faster than صحفبة - صكفية). Alternatively, if diacritical marks are assembled at the very early stages of word processing, each of the letters that compose the stimulus would only activate its corresponding best-letter match-in this scenario, we would only expect an advantage of the identity condition over the two substituted-letter priming conditions.

\section{MATERIALS AND METHODS}

\section{Participants}

Twenty-seven university students from Qatar University participated voluntarily in the experiment. All of them were native speakers of Arabic with normal or corrected-to-normal vision. The Ethics Committee of Qatar University approved this experiment. All participants gave written informed consent in accordance with the Declaration of Helsinki.

\section{Materials}

We selected 264 Arabic words of five letters, all of them with productive roots, from the Aralex database of Modern Standard Arabic (Boudelaa and Marslen-Wilson, 2010). The mean frequency per million in the Aralex database was 11.7 (range: 0.01-255.5). All the stimuli had a critical pairs of letters

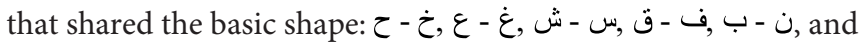
$ت$ ـ Each target word was preceded by a prime stimulus that was: (a) identical to the target (e.g., صحفية - صحفية SHfypSHfyp; identity condition); (b) identical to the target except for the substitution of a root letter with another letter that kept the basic shape (صحفبة - صخفبة Sxfyp- SHfyp; same-shape substituted-letter condition); or (c) the same as the target except for the substitution of the critical letter with another letter with a different basic shape while keeping the ligation pattern (Skfyp- SHfyp; different-shape substituted-letter condition). We prepared three lists to rotate the target words across the three priming conditions in a Latin square designthere were 88 items/condition. We also created a set of 264 nonwords of five letters in Arabic to be used as foils in the lexical 
decision task. These nonwords have been created by replacing one or two letters from an Arabic word (e.g., the nonword أونام $>$ wnAm was created by changing one letter from the word أوهام > wham [illusions]). The prime-target manipulation was the same as that for word targets. Nine participants were randomly assigned to each list. The set of stimuli is available at: http://www. uv.es/mperea/DiacriticsArabic.pdf

\section{Procedure}

The experimental session took place individually in a silent lab. To present the stimuli and collect the participant responses, we used a Windows-OS computer equipped with DMDX (Forster and Forster, 2003). All the stimuli (mask, prime, target) were displayed in the same spatial location at the center of the screen. The setup of a given trial was the following: (a) a mask composed of \#'s was presented for $500 \mathrm{~ms}$; (b) the prime was presented for $50 \mathrm{~ms}$; and (c) the target was presented until the participant responded or $2 \mathrm{~s}$ had passed. To prevent visual continuity, the font size of the prime (DejaVu Sans Mono 14-pt; i.e., a fixedwidth font) was smaller than that of the target (DejaVu Sans Mono 28-pt; see Perea et al., 2013, 2014). Participants were instructed to press the "yes" button if the letter string was an Arabic word and to press the "no" button otherwise. They were asked to make this decision as rapidly and as accurately as possible. Participants were not informed about the presence of briefly presented stimuli, and they did not report having seen them when asked after the experiment. Sixteen practice trials preceded the 528 experimental trials - the order of experimental trials was fully randomized for each participant. The whole session lasted for around 21-25 $\mathrm{min}$.

\section{RESULTS}

Response times (RTs) shorter than $250 \mathrm{~ms}$ were removed from the correct RT analyses. The mean correct RTs and accuracy for word and nonword targets in each experimental condition (identity condition, same-shape substituted letter prime; different-shape substituted letter prime) are displayed in Table $\mathbf{1}$.

The correct RT data were analyzed using linear mixed-effects models in R ( $\mathrm{R}$ Core Team, 2016). For the word trials, there were 6375 data points in the RT analyses-for the nonword trials, the data points were 5819. As RT distributions show positive asymmetry, raw RTs were inverse-transformed $(-1000 / \mathrm{RT})$ to maintain the Gaussian assumption of liner mixed-effects models. The coding of the fixed factor "Prime-target relationship" tested the two contrasts of interest: (a) identity prime vs. same-shape substituted-letter prime; and (b) same-shape substituted-letter prime vs. different-shape substituted-letter prime. We employed the package lme4 (Bates et al., 2015) to obtain $t$-values, and the package lmerTest (Kuznetsova et al., 2016) to obtain the corresponding $p$-values. With respect to the random effects, we employed the maximal random effects structure model. That is, the resulting model for the latency analyses of word trials was the following: LME_WordRTs $=$ lmer(inv_RT type_of_prime + (type_of_prime $+1 \mid$ item) + (type_of_prime +1 (subject), data $=$ WordRTs) - the model for the nonword trials was parallel except that we had NonwordRTs instead of WordsRTs. The accuracy data were modeled using the glmer
TABLE 1 | Mean response times (in ms) and accuracy (in parentheses) for words and nonwords in the three prime-target conditions of the experiment.

\begin{tabular}{lccc}
\hline & Identity & $\begin{array}{c}\text { Same shape } \\
\text { substituted-letter }\end{array}$ & $\begin{array}{c}\text { Different shape } \\
\text { substituted-letter }\end{array}$ \\
\hline Words & $758(0.898)$ & $777(0.890)$ & $775(0.895)$ \\
Nonwords & $869(0.822)$ & $883(0.803)$ & $868(0.825)$ \\
\hline
\end{tabular}

function (family = binomial) and the data were coded as binary values ( 0 vs. 1 ). From the glmer summary command, we obtained $z$-values and their corresponding $p$-values.

\section{Word Data}

The lexical decision data showed a 19-ms advantage of the identity condition over the same-shape substituted-letter conditions, coefficient $=-0.0368, S E=0.0103, t=-3.59$, $p<001$, while there were no signs of a difference between the same-shape and different-shape substituted-letter conditions, coefficient $=-0.0043, S E=0.0126, t=0.34, p>0.73$. Finally, a post hoc analysis showed that the $17 \mathrm{~ms}$ advantage of the identity condition over the different-shape substituted-letter condition was statistically significant, coefficient $=-0.00326, S E=0.0101$, $t=3.22, p=0.002$.

The analyses of the accuracy data failed to find any significant effects, both $|z s|<1$.

\section{Nonword Data}

The analyses of the RT data for nonwords did not show any trends of an effect, both $|t s|<1$. The analyses of the accuracy data only showed a small (1.8\%) advantage of the identity condition over the same-shape substituted-letter condition that approached significance, coefficient $=-0.16065, S E=0.08215, z=1.95$, $p=0.051$, whereas there were no signs of a difference between same-shape and different-shape substituted-letter conditions, $|z|<1$.

\section{DISCUSSION}

The current masked priming lexical decision experiment showed that substituted-letter primes in which the replaced letter kept the same basic shape as the original letter (e.g., صحفية - صخفية) were not more effective at activating the base words than substituted-letter primes in which the replaced letter was visually different (e.g., صحفية - صكفية) (i.e., a $-2 \mathrm{~ms}$ difference). The null effect for the two substituted-letter primes was not due to lack of processing of the primes, as we found a significant 19-ms advantage of the identity condition over the same-shape substituted-letter priming condition.

These findings support the view that there is fast access to abstract representations in Arabic (see Carreiras et al., 2012, 2013; Perea et al., 2013): each letter (e.g., $\dot{\varepsilon}$ ) activates quickly its corresponding letter representation so that the visually similar letter $\varepsilon$ is no more effective in activating its abstract representation than a visually dissimilar letter (e.g., ص). Another important implication of the present experiment is that diacritical information is highly relevant in the "letter 
feature" level of Arabic, as it is key to distinguishing among many letters that otherwise share the same basic shape. Keep in mind that, as indicated in the Introduction, the majority of Arabic letters share their basic shape with at least one other letter. Failing to correctly identify the right letter would necessarily produce a reading cost. Consistent with this view, in a recent study with pairs of isolated letters in Arabic, Wiley et al. (2016) found that the diacritic marks were the "the most important feature (...) for both discrimination time and accuracy."

Current neural and computational models of visual word recognition have focused on the Roman alphabet, and more specifically, on the orthographic and lexical levels. A limitation of these models is the lack of a detailed specification of the "letter feature" level and how this level is mapped onto the "abstract" letter level-for instance, current computational models of visual word recognition still use the unrealistic uppercase font devised by Rumelhart and Siple (1974) (see Blais et al., 2009; Davis, 2010; Rosa et al., 2016, for discussion). The special characteristics of the Arabic alphabet raises a number of questions (e.g., position-dependent allography, diacritical marks, and its cursive nature) that may help implement a more comprehensive model of visual word recognition in alphabetic languages.

\section{REFERENCES}

Bates, D., Maechler, M., Bolker, B., and Walker, S. (2015). Fitting linear mixedeffects models using lme4. J. Stat. Softw. 67, 1-48. doi: 10.18637/jss.v067.i01

Blais, C., Fiset, D., Jolicoeur, P., Arguin, M., Bub, D. N., and Gosselin, F. (2009). Reading between eye saccades. PLoS ONE 4:e6448. doi: 10.1371/journal.pone.0006448

Boudelaa, S., and Marslen-Wilson, W. D. (2010). Aralex: a lexical database for Modern Standard Arabic. Behav. Res. Methods 42, 481-487. doi: 10.3758/brm.42.2.481

Bowers, J. S., Vigliocco, G., and Haan, R. (1998). Orthographic, phonological, and articulatory contributions to masked letter and word priming. J. Exp. Psychol. Hum. 24, 1705-1719. doi: 10.1037/0096-1523.24.6.1705

Carreiras, M., Perea, M., and Abu Mallouh, R. (2012). Priming of abstract letter representations may be universal: the case of Arabic. Psychon. Bull. Rev. 19, 685-690. doi: 10.3758/s13423-012-0260-8

Carreiras, M., Perea, M., Gil-López, C., Abu Mallouh, R., and Salillas, E. (2013). Neural correlates of visual vs. abstract letter processing in Roman and Arabic scripts. J. Cognit. Neurosci. 25, 1975-1985. doi: 10.1162/jocn_a_00438

Davis, C. J. (2010). The spatial coding model of visual word identification. Psychol. Rev. 117, 713-758. doi: 10.1037/a0019738

Forster, K. I., and Forster, J. C. (2003). DMDX: a windows display program with millisecond accuracy. Behav. Res. Methods 35, 116-124. doi: 10.3758/bf03195503

Grainger, J., Dufau, S., and Ziegler, J. C. (2016). A vision of reading. Trends Cogn. Sci. 20, 171-179. doi: 10.1016/j.tics.2015.12.008

Jacobs, A. M., Grainger, J., and Ferrand, L. (1995). The incremental priming technique: a method for determining within-condition priming effects. Percept. Psychophys. 57, 1101-1110. doi: 10.3758/bf03208367

Kinoshita, S., Robidoux, S., Mills, L., and Norris, D. (2013). Visual similarity effects on masked priming. Mem. Cogn. 42, 821-833. doi: 10.3758/s13421-013-0388-4

Kuznetsova, A., Brockhoff, P. B., and Christensen, R. H. B. (2016). lmerTest: Tests for Random and Fixed Effects for Linear Mixed Effect Models (lmer Objects of lme4 Package): R Package Version 2.0-30. Available online at: https://cran.rproject.org/web/packages/lmerTest/index.html

Okano, K., Grainger, J., and Holcomb, P. J. (2013). An ERP investigation of visual word recognition in syllabary scripts. Cogn. Affect. Behav. Neurosci. 13, 390-404. doi: 10.3758/s13415-013-0149-7
In sum, diacritical marks in Arabic are the only visual element that distinguishes a large percentage of Arabic letters. The present experiment demonstrated that this information is rapidly processed by the cognitive system, even when the prime stimulus is presented very briefly $(50 \mathrm{~ms})$ and is forwardly and backwardly masked. Therefore, at the early stages of word processing in Arabic, the cognitive system of adult readers is able to distinguish between identity priming condition (e.g., صحفية - صحفية) and a same-shape substituted-letter condition that only varies in the number of diacritics (e.g., صحفبة - صكفية). Further research should examine whether developing readers can tell apart these seemingly visually-similar words early in processing and whether reading skill (e.g., good vs. bad readers) modulates this process.

\section{AUTHOR CONTRIBUTIONS}

MP, MC, RA, BK, and AM designed the experiment. RA prepared the materials. AM conducted the experiment. MP and MC analyzed the data. MP and MC wrote the initial draft.

\section{FUNDING}

The research reported in this article has been supported by Grant NPRP No. 6-378-5-035 from Qatar Foundation.

Perea, M., Abu, M., and Carreiras, M. (2014). Are root letters compulsory for lexical access in Semitic languages? The case of masked form-priming in Arabic. Cognition 132, 491-500. doi: 10.1016/j.cognition.2014.05.008

Perea, M., Duñabeitia, J. A., and Carreiras, M. (2008). R34D1NG W0RD5 W1TH NUMB3R5. J. Exp. Psychol. Hum. 34, 237-241. doi: 10.1037/0096-1523.34.1.237

Perea, M., Mallouh, R. A., and Carreiras, M. (2013). Early access to abstract representations in developing readers: evidence from masked priming. Dev. Sci. 16, 564-573. doi: 10.1111/desc.12052

R Core Team (2016). R: A Language and Environment for Statistical Computing. Vienna: R Foundation for Statistical Computing.

Rosa, E., Perea, M., and Enneson, P. (2016). The role of letter features in visualword recognition: evidence from a delayed segment technique. Acta Psychol. 169, 133-142. doi: 10.1016/j.actpsy.2016.05.016

Rumelhart, D. E., and Siple, P. (1974). Process of recognizing tachistoscopically presented words. Psychol. Rev. 87, 99-118. doi: 10.1037/h0036117

Vergara-Martínez, M., Gómez, P., Jiménez, M., and Perea, M. (2015). Lexical enhancement during prime-target integration: ERP evidence from matchedcase identity priming. Cogn. Affect. Behav. Neurosci. 15, 492-504. doi: 10.3758/s13415-014-0330-7

Wiley, R. W., Wilson, C., and Rapp, B. (2016). The effects of alphabet and expertise on letter perception. J. Exp. Psychol. Hum. Percept. Perform. 42, 1186-1203. doi: $10.1037 / x h p 000213$

Yakup, M., Abliz, W., Sereno, J., and Perea, M. (2015). Extending models of visual-word recognition to semicursive scripts: evidence from masked priming in Uyghur. J. Exp. Psychol. Hum. 41, 1553-1562. doi: 10.1037/xhp00 00143

Conflict of Interest Statement: The authors declare that the research was conducted in the absence of any commercial or financial relationships that could be construed as a potential conflict of interest.

Copyright (C) 2016 Perea, Abu Mallouh, Mohammed, Khalifa and Carreiras. This is an open-access article distributed under the terms of the Creative Commons Attribution License (CC BY). The use, distribution or reproduction in other forums is permitted, provided the original author(s) or licensor are credited and that the original publication in this journal is cited, in accordance with accepted academic practice. No use, distribution or reproduction is permitted which does not comply with these terms. 